\title{
Financiamiento para construir la finca Túpac Barahona
}

Resumen.- Las instituciones financieras convencionales y no convencionales tienden a excluir de los servicios de crédito a los sectores más frágiles del campesinado, por considerarlos clientes altamente riesgosos. En este artículo, se discute el sentido económico y social que tendrían que desarrollar esquemas de financiamiento para campesinos con economías débiles, pero con un potencial de desarrollo latente.

\section{¿Por qué invertir en un cliente riesgoso?}

"El crédito es un negocio. Como tal, debe dirigirse hacia clientes que demuestran un claro respaldo material y moral para pagar las deudas". Así piensan, con justa razón, los gerentes de las entidades de financiamiento no convencional (y, por supuesto, los de la banca comercial), preocupados por la eficiencia y la sostenibilidad de sus operaciones. Ante esta regla del oficio, los sectores más frágiles del campesinado, que sólo poseen una pequeña parcela de tierra, cuya tenencia es aún insegura, definitivamente no califican como sujetos de crédito. Según esta manera de ver las cosas, lo más saludable sería orientar la cartera crediticia hacia los estratos más acomodados del campesinado (los "finqueros") o vinculados al comercio de pequeña escala y a los servicios de transporte, priorizando inversiones de rápido retorno.

La lógica de excluir a los campesinos con economías volátiles parece perfectamente justificada. Su fragilidad se deja ver desde casi cualquier ángulo: legal, productivo, comercial, ecológico, social. El caso más evidente, aunque no el único, es el de los beneficiarios de la reforma agraria, que durante los años ochenta fueron mantenidos y organizados artificialmente desde el Estado, en forma de cooperativas de producción que hoy se desmoronan una vez cortado el cordón umbilical por donde fluía el apoyo gubernamental. La mayoría de estos campesinos cooperativizados se han repartido las tierras y cada familia es ahora dueña de una parcela. Pero la apropiación está inconclusa: muchos no cuentan con una escritura debidamente inscrita en el Registro de la Propiedad y carecen de la infraestructura básica de protección y asentamiento (una cerca, una casa, etc.). Todavía persiste un clima de inseguridad y los parceleros se sienten inhibidos para emprender iniciativas de inversión.

Sus tierras están "peladas". La fertilidad natural del suelo se ha deteriorado después de varios años de cultivo sin reincorporación de materia orgánica. No existen árboles que suavicen las ráfagas 
de viento o den un poco de sombra donde puedan refugiarse las gallinas. Las lluvias abren pequeños cauces por donde arrastran la tierra dada la falta de obras de conservación de suelos. La incertidumbre del parcelero va más allá de la propiedad, pues sus tierras también son ecológicamente frágiles.

En coherencia con lo anterior, su economía es muy inestable. Vienen de cultivar granos básicos (maíz, sorgo, etc.) en las grandes extensiones que las cooperativas manejaron colectivamente. Tienen que empezar de cero, pues no tienen prácticamente ningún tipo de inversión permanente: ni frutales, ni ganado, ni chagüite, ni gallinas siquiera. Dependen casi exclusivamente de las siembras de granos que puedan realizar en el año. Y si a la mitad del ciclo agrícola se instala una sequía o una racha de aguaceros excesivos, pierden sus cultivos y sus esperanzas de cosecha.

Como hay pocas inversiones en la tierra, la familia se dedica muy poco al trabajo en la parcela. Los varones adultos buscan trabajo eventual como jornaleros en alguna finca vecina. Las mujeres adultas ofrecen sus servicios como empleadas domésticas en alguna ciudad cercana, $o$ salen a ganar algún jornal, como los varones. Los niños crecen sin aprender cómo se maneja una finca $y$, en muchos casos, no asisten a la escuela por mucho tiempo. Como resultado, las familias se desintegran, no permanecen unidas por mucho tiempo. El arraigo social y el prestigio que pueden cultivar estos campesinos pobres no llega muy lejos.
Por todas estas razones, a los gerentes del crédito no les conviene colocar plata en un campesino que no sabe si la tierra es suya, o si va a poder alimentar a sus hijos el próximo verano, y que además no goza de mucha simpatía entre sus vecinos. ¿Por qué una institución de crédito se interesaría por financiar a alguien que no tiene un sólido respaldo económico y moral? La respuesta negativa podría ser muy apresurada.

Para una entidad de financiamiento con perspectiva de desarrollo podría ser interesante identificar y apoyar a sectores que muestran un potencial económico latente, pero que no lo pueden desplegar a causa de alguna de las debilidades que hemos mencionado. $\mathrm{Al}$ restringir el acceso al crédito a los campesinos más vulnerables, podemos estar reforzando la marginación de alguien que, con algún empujón, podría convertirse en un finquero viable, pero sobre todo en un buen cliente que cumple oportunamente con sus compromisos crediticios. La institución financiera podría también expandir su cartera en un mismo territorio, sin incurrir en muchos costos adicionales. Y sobre todo haría una importante contribución al desarrollo local y nacional.

Obviamente, invertir en la construcción de estos buenos clientes y buenos miembros de la comunidad, conlleva gastos extras y riesgos significativos, y la institución financiera debe estar consciente de ello. No se trata de una cartera de alta rentabilidad en el corto plazo, sino de una contribución a mejorar el entorno social actual, que redundará en beneficios futuros 
para la entidad financiera y contribuirá al desarrollo de la sociedad en su conjunto.

\section{La finca como una máquina integral}

El interés de financiar a los sectores frágiles del área rural no proviene de una vocación meramente altruista, ni de un sentido de compensación social para paliar la pobreza. Por el contrario, nace de una visión de rentabilidad a largo plazo que ve la posibilidad de que estas pequeñas economías que hoy se encuentran desintegradas y desarticuladas del resto del tejido social, se transformen con el tiempo en una "máquina" económica integral y bien insertada en los mercados.

Mirando hacia otros campesinos más desarrollados, podemos identificar algunos rasgos que caracterizarían este modelo de pequeña finca integral.

- "La máquina" tiene variados componentes que se cuidan y complementan unos a otros, atendiendo a una lógica de disminuir los riesgos y enfrentar las eventualidades negativas. Por ejemplo, la finca de un campesino de Masaya que ha desarrollado una producción diversificada cuenta con una serie de rubros que le permiten obtener ingresos durante todo el año (ver gráfico 1). Durante el verano, en vez de emigrar a Costa Rica en busca de trabajo, vende la cosecha de jocote, mango y tamarindo. Con sus ganancias compra los cuadernos y libros que sus hijos necesitan en la escuela, y se autofinancia los insumos y la preparación de tierras para los cultivos de invierno. Si quitáramos todos los cultivos perennes y los frutales que el campesino posee, se quedaría sin ingresos significativos durante el verano y los primeros meses del invierno. Sería tan frágil como el parcelero.

\section{Gráfico 1}

DISTRIBUCIÓN ANUAL DE INGRESOS DE DIFERENTES RUBROS DE LA FINCA (CASO: CAMPESINO DIVERSIFICADO DE LA ZONA CENTRAL DE MASAYA)

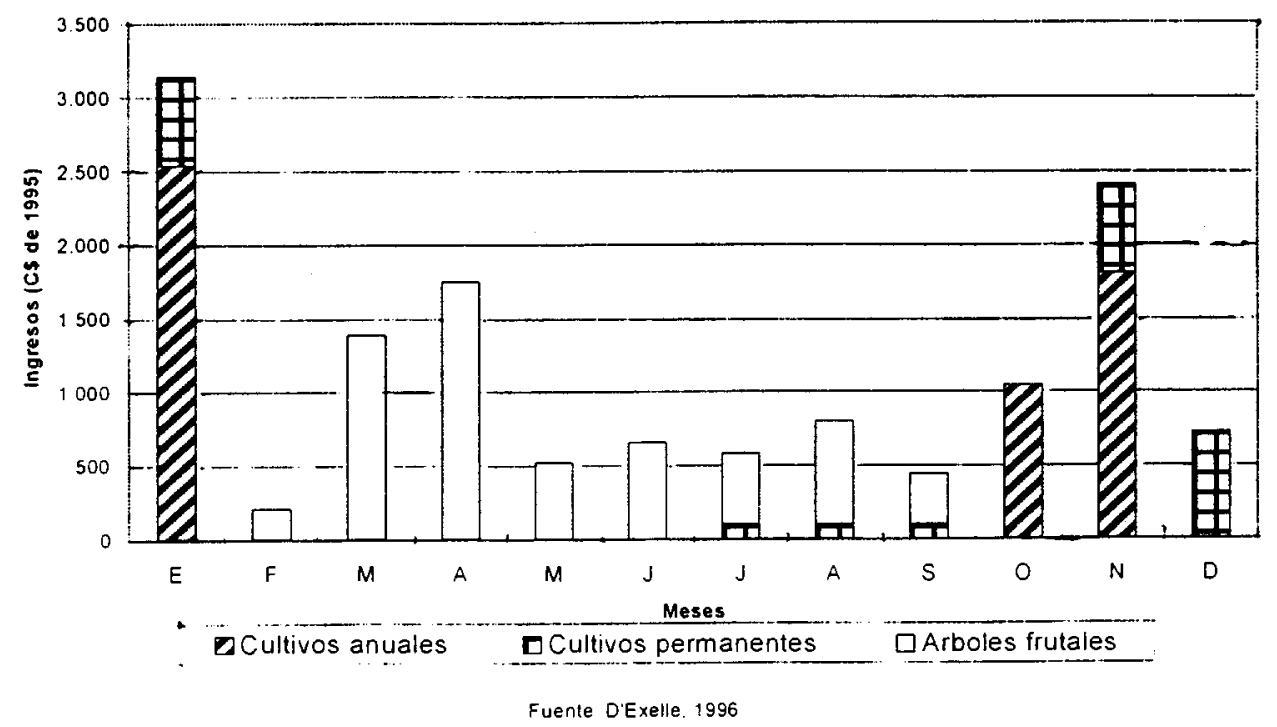


- Los recursos se aprovechan al máximo, se hace un uso intensivo de ellos. Cada palmo de tierra está cubierto con algún árbol, planta o cultivo; no hay áreas ociosas. Los residuos de la producción siempre se aprovechan: se construyen aboneras con el estiércol del ganado, se alimenta al ganado con los rastrojos de los cultivos anuales. Los miembros de la familia se mantienen suficientemente ocupados. Si los niños no están en la escuela están ayudando a pastorear los animales o ayudando con los cultivos.

- Hay un equilibrio entre tecnología y mano de obra. El desarrollo tecnológico de la finca depende mucho de las destrezas y habilidades que desarrollan los trabajadores y no tanto de la incorporación de insumos y maquinaria pesada y costosa. Para elevar la productividad de una parcela de café, por ejemplo, en vez de gastar en grandes cantidades de fertilizante sintético, se utiliza el estiércol de gallinas para fertilizar y se realizan cuidadosas labores de poda para mantener árboles vigorosos.

- Se cuida la calidad de los recursos, se mantiene o incrementa su valor. Se cuida la tierra para que no pierda su fertilidad. El chagüite viejo se repone con cepas nuevas. Los bueyes, en vez de depreciarse, adquieren un mayor valor cualitativo y de mercado a medida que crecen y se vuelven más diestros y educados.

- La propia familia campesina desarrolla nuevas capacidades. Desarrolla una compleja capacidad gerencial que le permite manejar eficientemente "la máquina". Desarrolla su curiosidad y su espíritu innovador, experimentando nuevas tecnologías caseras y nuevas formas de organizar la producción. Desarrolla su capacidad de conectarse mejor con el mercado y establecer redes de apoyo y colaboración mutua.

En esta perspectiva de finca integral, la eficiencia no está asociada necesariamente al tamaño de la propiedad o a la cantidad de maquinarias e insumos externos que ha adquirido. Un pequeño campesino de la meseta de Carazo que maneja cuidadosamente su cafetal mediante podas y regulación de la sombra de árboles maderables puede obtener rendimientos de hasta 50 fanegas(1) por manzana, gastando muy pocos insumos. Para obtener el mismo rendimiento, los hacendados cafetaleros de la zona necesitan de 2 a 3 manzanas en vez de una, y gastar más en fertilizantes y plaguicidas comerciales.

En este sentido, la "fragilidad" no es patrimonio exclusivo de las economías de los pequeños campesinos descapitalizados, pues los productores extensivos que manejan buena parte de sus tierras semi-ociosas también pueden considerarse "frágiles". La diferencia es que estos últimos viven más cómodamente y tienen una mayor nivel de influencia dentro de la política local o nacional.

En base a todo lo anterior, a la institución financiera que piensa en el largo plazo no le conviene ver con indiferencia la necesidad de dinamizar al sector de campesinos y finqueros. Si es posible concretar esta transición del campesinado más débil hacia un sector de pequeños finqueros dinámicos, es de esperar que 
mejoren también las perspectivas de las instituciones que ofertan servicios de crédito en el área rural, pues se supone que "si mejora el cliente, mejora el banco".

\section{El modelo de crédito "Los Arboles Valen".}

Animado por esta perspectiva, el Instituto Nitlapán de la Universidad Centroamericana, inició en 1995 un programa experimental para fomentar la capitalización de los sectores frágiles del campesinado(2) que complementara las operaciones normales de su programa de crédito no convencional que atiende a sectores más consolidados. Este nuevo programa, llamado "Los Arboles Valen" (LAV), se inició en el departamento de Masaya, principalmente con parceleros beneficiados por la reforma agraria y algunos pequeños campesinos más desarrollados, con un fuerte componente de fomento de la arborización como una de las actividades claves para la construcción y capitalización de la finca.

LAV diseñó un modelo de crédito especial para fomentar la capitalización de los parceleros, en el cual la presencia de árboles en la finca da acceso a financiamiento de largo plazo que permite realizar otras inversiones claves que la finca necesita, tales como construir una casa, comprar animales de patio y hasta ganado, establecer una plantación de chagüite o café, etc. La familia tiene la libertad de utilizar el crédito en las inversiones que estima más conveniente, mientras los árboles se van desarrollando $\mathrm{y}$ funcionan como un respaldo adicional ante el compromiso de pago en el futuro. Los costos monetarios directos de producir los árboles son muy pequeños, y la parte del crédito que se gasta en la producción forestal en sí, difícilmente excede el 10\% del monto del crédito (ver gráfico 2).

Gráfico 2

USO DECLARADO DEL CRÉDITO LAV (1996/97)

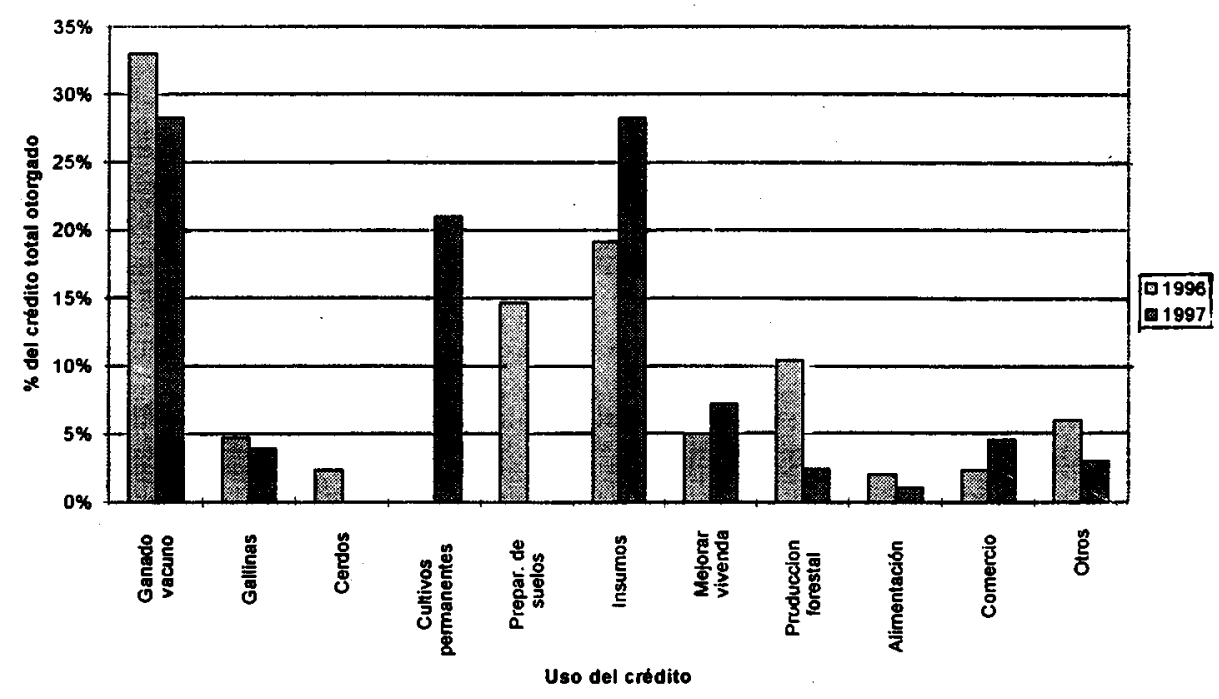


Además de esta línea de crédito forestal de uso flexible, LAV cuenta también con otras dos líneas de crédito dirigidas más específicamente al aseguramiento y protección de la propiedad: a) un financiamiento que cubre los gastos del servicio de topografía y escrituración de la parcela, realizado por un equipo legal especializado de Nitlapán, y b) un alambre, grapas, etc.) para la construcción de la cerca perimetral que protege la parcela y/o divisiones internas dentro de la misma. La cerca es un factor clave para proteger las futuras inversiones (entre ellas los árboles) del daño de animales y vecinos. En el cuadro 1 se sintetizan las principales políticas del crédito LAV hasta 1997.

financiamiento en especies (postes,

Cuadro 1

POLITICA DE CRĖDITO LAV

\begin{tabular}{|c|c|c|c|}
\hline Linea de crédito & Escrituración & Cercas Vivas & Forestal (Integral) \\
\hline $\begin{array}{l}\text { Requisitos para } \\
\text { ser sujeto de } \\
\text { credito }\end{array}$ & $\begin{array}{l}\text { - Tener legalizada la } \\
\text { - Vivir o tener preser } \\
\text { - Contar con un } \\
\text { permanentes en la } \\
\text { - Tener buena reputa } \\
\text { - Poner una prenda } \\
\text { - Presentar un codeu }\end{array}$ & $\begin{array}{l}\text { propiedad o estar en proceso } \\
\text { ncia constante en la parcela } \\
\text { minimo de diversificación } \\
\text { propiedad } \\
\text { ación en la comunidad } \\
\text { material como garantía del cré } \\
\text { udor que también se responsab }\end{array}$ & $\begin{array}{l}\text { de hacerlo } \\
\text { productiva e inversiones } \\
\text { édito } \\
\text { bilice del crédito }\end{array}$ \\
\hline Monto prestado & US\$ 80 promedio. & 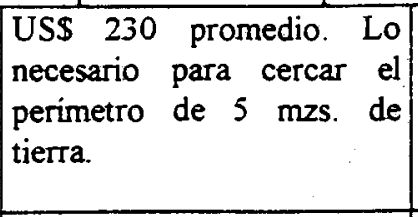 & $\begin{array}{l}\text { USS } 0.25 \text { por arbol por } \\
\text { año, durante } 3 \text { años. Para } \\
\text { un total de USS } 0.75 \text { por } \\
\text { arbol. Monto promedio por } \\
\text { socio: US\$ } 480\end{array}$ \\
\hline Desembolsos & $\begin{array}{l}\text { No se desembolsa dinero en } \\
\text { efectivo. El crédito se carga } \\
\text { a medida que avanza el } \\
\text { servicio de escrituración. }\end{array}$ & $\begin{array}{l}\text { No se desembolsa dinero. } \\
\text { Se entregan los materiales } \\
\text { necesarios para construir la } \\
\text { cerca (postes, alambre, } \\
\text { grapas). }\end{array}$ & $\begin{array}{l}\text { El socio puede optar, segun } \\
\text { su comportamiento, a un } \\
\text { máximo de } 3 \text { desembolsos } \\
\text { (1 desembolso por año), } \\
\text { que son computados como } \\
3 \text { préstamos difetentes. }\end{array}$ \\
\hline Tasa de interés & $4 \%$ anual s/ saido. & $8 \%$ y $12 \%$ anual s/ saido. & $8 \%$ y $12 \%$ anual s/ saido. \\
\hline $\begin{array}{l}\text { Mantenimiento } \\
\text { del valor } \\
\end{array}$ & \multicolumn{3}{|c|}{ Conforme al dólar estadounidense } \\
\hline Plazo de pago & 1 año. & 3 años. & 6 años. \\
\hline \begin{tabular}{|l|} 
Modalidad de \\
pago
\end{tabular} & 1 sola cuota al vencimiento. & $\begin{array}{l}3 \text { cuotas anuales (20\% ler. } \\
\text { Año, } 40 \% 2 \text { do. Año, } 40 \% \\
\text { Jer. Año) }\end{array}$ & $\begin{array}{l}\text { Se amortiza a partir del } 4 \text { to. } \\
\text { año. Cada préstamo o } \\
\text { desembolso tiene un plazo } \\
\text { de pago de } 4 \text { años. }\end{array}$ \\
\hline $\begin{array}{l}\text { Uso y control del } \\
\text { crédito }\end{array}$ & $\begin{array}{l}\text { Dirigido al servicio de } \\
\text { escrituración. }\end{array}$ & $\begin{array}{l}\text { Dirigido a la construcción } \\
\text { de cercas vivas. }\end{array}$ & $\begin{array}{l}\text { Uso flexible según la } \\
\text { planificación que haga la } \\
\text { familia. }\end{array}$ \\
\hline Garantías & $\begin{array}{l}\text { Retención de la escritura (el } \\
\text { papel, no la tierra). }\end{array}$ & \begin{tabular}{|l|}
$\begin{array}{l}\text { Prendas materiales bajo } \\
\text { contrato de mutuo. }\end{array}$ \\
\end{tabular} & \begin{tabular}{|l} 
Prendas materiales bajo \\
contrato de mutuo.
\end{tabular} \\
\hline
\end{tabular}

Algunos rasgos importantes de este modelo de crédito que cabe destacar son: - Apuesta al largo plazo como factor de capitalización. Se considera que el proceso de construcción de la finca es paulatino, $y$ que para incentivarlo no se puede exigir un reembolso rápido del dinero. Por eso, durante los primeros años del crédito forestal sólo se exige el pago de intereses y mantenimiento de valor, dejando la 
amortización del capital a partir del cuarto año.

- Construye la garantía de pago junto con el socio. Puesto que se trata de economías frágiles, las garantías de pago son inicialmente muy débiles, hay que construirlas. A pesar que formalmente se exige una prenda material como garantía, normalmente los parceleros no tienen bienes de valor rápidamente ejecutables. Por tanto, se espera que la misma inversión forestal, así como la diversidad de otras producciones futuras, sean las verdaderas garantías. En este sentido, más que de un crédito (aunque esta sea su figura formal), se trata de una coinversión.

- Se trata de un crédito semi-dirigido, en el que LAV pone ciertas condiciones de acceso y uso del crédito para garantizar un mínimo de éxito de las inversiones (cercas, árboles), pero deja también un margen de decisión bastante amplio a la familia.

\section{La dinámica de capitalización y construcción de la finca}

Después de 3 años de funcionamiento de LAV (1995-1998), es posible adelantar algunas observaciones sobre la dinámica de la capitalización que siguen los parceleros que trabajan con LAV, en el proceso de construcción de su finca. No pretendemos aquí medir o evaluar con exactitud el impacto de LAV en dicha capitalización, sino más bien mostrar las formas que ha tomado este proceso.

Diferentes rutas y velocidades

El proceso de capitalización no es homogéneo entre todos los parceleros. $\mathrm{Al}$ inicio, prácticamente todos necesitan un mínimo de aseguramiento legal y de protección física (escritura y cercas). Es el primer paso que apoya el programa LAV. Sin embargo, la continuación del proceso depende más de la gestión del propio parcelero y de sus propios recursos. De ahí en adelante, la capitalización toma diferentes rutas y velocidades (Marín, 1998).

Los parceleros comienzan a diferenciarse, tomando perfiles específicos:

a) En la zona norte de Masaya, donde las condiciones climáticas son más adversas y es más difícil establecer cultivos permanentes como el café o el chagüite, los parceleros siguen sembrando cultivos anuales, aunque tienden a diversificar su producción e introducir rubros que no tenían antes: tubérculos como la yuca y el quequisque, hortalizas como el pipián y el ayote. Los más avanzados logran invertir en un mínimo de ganado: una pareja de terneros para educarlos como bueyes, o alguna vaca adulta. El establecimiento de árboles maderables y leñeros se organiza en pequeñas parcelas compactas o en las rondas y cercos de la finca. Se estructura así un perfil de agricultor diversificado-pequeño ganadero.

b) En la zona central más cercana a Masaya, el perfil de inversiones del parcelero se orienta más hacia ciertos rubros permanentes como el chagüite y el cultivo de una gran variedad de árboles frutales: jocote, mamón, nancite, tamarindo, icaco, mango, aguacate, etc., que constituyen una fuente de ingresos fundamental durante el verano y los 
primeros meses del invierno. Los árboles maderables y leñeros están asociados con los frutales. La agricultura no se abandona, pero se restringe a pequeñas áreas para garantizar la alimentación de la familia. Las inversiones en ganado también están presentes, pero de forma menos extendida que en la zona norte. Tenemos pues un perfil de fruticultor diversificado.

c) Al sur de Masaya la presencia y variedad de cultivos permanentes es aun mayor, destacándose las asociaciones de café, chagüite y árboles de todo tipo; los cultivos de enramadas como la calala y granadilla, y otros rubros permanentes como la piña y la pitahaya. Se trata de verdaderos policultivistas.

Además de tomar diferentes rutas, los parceleros avanzan (y/o retroceden) a distintas velocidades, incluso dentro de una misma zona donde las condiciones son similares (ver gráfico 3). No todos logran establecer las inversiones claves que requieren para consolidarse como campesinos. Después de cercar su propiedad, algunos se quedan siempre con los cultivos anuales, dependiendo de los caprichos del clima y el mercado. Eventualmente, en vez de avanzar, van "como el cangrejo" (un 20\% de los socios LAV).

Otros, por el contrario, avanzan a ritmos vertiginosos, construyendo su casa, trasladándose a vivir a la parcela, estableciendo cultivos permanentes, adquiriendo medios de transporte como carretas o carretones, etc. (40\% de los socios). También encontramos parceleros que llevan un ritmo de avance relativamente lento pero sostenido (el otro $40 \%$ de los socios), comenzando con modestas inversiones que van consolidando poco a poco, como el establecimiento de árboles frutales, maderables y leñeros (Ocdé, 1997).

Gráfico 3

EVOLUCIÓN DEL NIVEL DE CAPITAL/MZ DE TRES TIPOS DE PAR CELERO

(ZONA NORTE DE MASAYA)

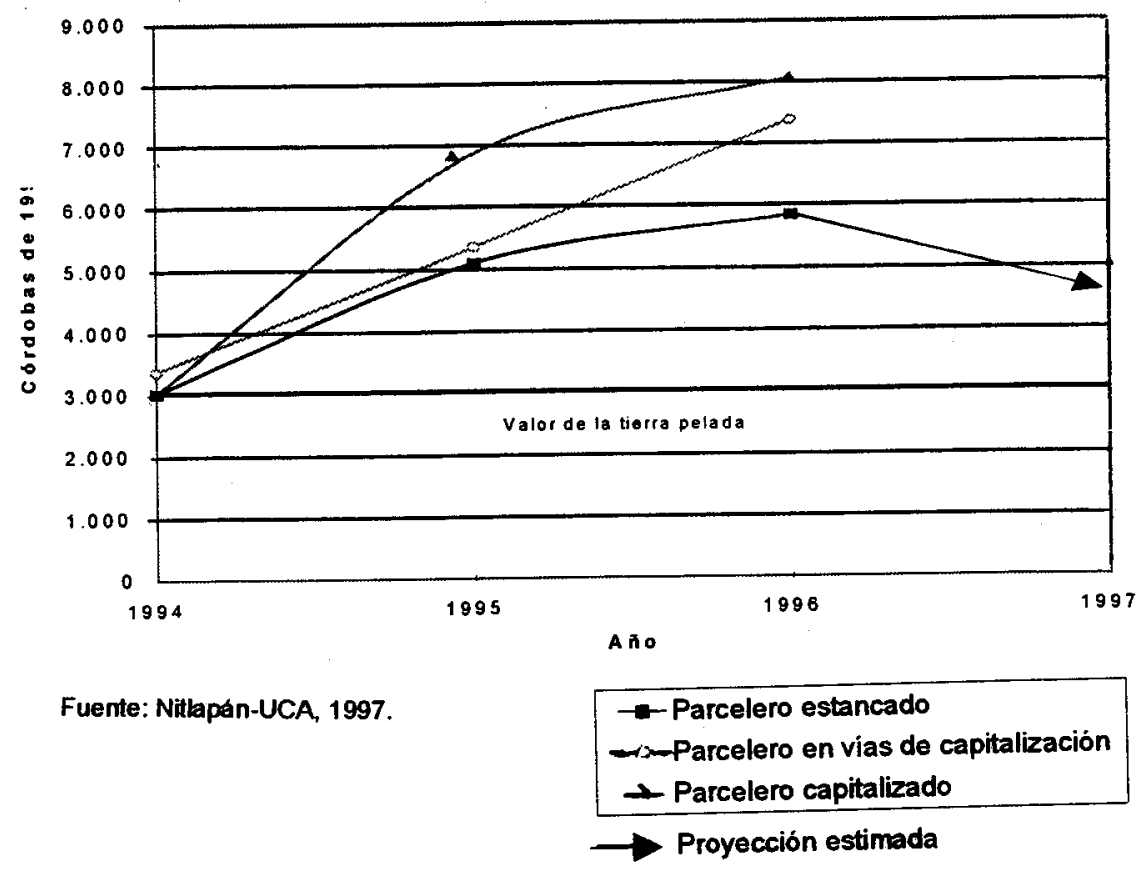




\section{Factores de éxito}

¿Cómo explicar estas diferencias en el avance de los parceleros? Entre los factores de éxito que más se destacan está la capacidad de movilizar la mano de obra familiar para trabajar y cuidar la finca (Barahona, 1997). Las personas de mayor edad que no cuentan con mucho apoyo de sus hijos y nietos se quedan solos cuidando la parcela y tratando de trabajarla, enfrentando demasiadas dificultades: amenazas de robo, sobrecarga de trabajo (cultivar, cocinar, conseguir el agua, etc.), problemas para garantizar la comida diaria. En las familias más exitosas, en cambio, hay una mayor integración y complementariedad del trabajo familiar. Mientras la señora sale al mercado para vender algunas hortalizas de la finca y con el dinero compra la comida diaria, el señor está atendiendo los cultivos con ayuda de sus hijos pequeños, mientras la hija mayor trabaja como doméstica en la ciudad y aporta algún dinero para comprar los insumos y materiales que se necesitan en la finca.

La movilización de la mano de obra es un asunto no solamente de cantidad, sino de calidad. Manejar una finca es un arte, y se necesita mucha experiencia para tener éxito. Es notable que los campesinos de la zona sur, que han nacido y crecido en un medio donde se cultivan una gran diversidad de rubros, cuentan con un gran bagaje de conocimientos. Algunos de estos campesinos minifundistas del sur recibieron una parcela de tierra de la reforma agraria en la zona norte, y han aplicado su modelo de diversificación a las tierras que estaban peladas. Su ritmo de avance es asombroso en comparación con los parceleros originarios de las propias comarcas del norte.

Además de làs capacidades subjetivas de cada familia, también influye en el éxito la posibilidad de concretar algunas inversiones mínimas para el despegue. Tener acceso al agua potable y levantar una casa rústica son estímulos importantes para que la familia pueda asentarse más permanentemente en la parcela. Para iniciar el cultivo de rubros permanentes se necesita conseguir el material vegetal reproductivo: las cepas del chagüite, las plantitas de café, las ramas de jocote, los hijos de piña, las guías de pitahaya. Una vez establecido el cultivo, su viabilidad depende más del cuido que le de la familia, pero al principio el factor crítico es el mínimo de capital necesario para conseguir estos materiales. En este sentido, el crédito LAV ha contribuido parcialmente a resolver este cuello de botella. En otros casos, como el de las cooperativas cafetaleras del sur, los parceleros tenían la ventaja inicial de haber "heredado" un pedazo de tierra que no estaba completamente pelado, sino que tenía un poco de café y algunos árboles frutales.

\section{Efectos positivos más evidentes}

Entre los efectos positivos más evidentes que viven las familias que han logrado avanzar en su proceso de capitalización están:

- Aumento del valor de la tierra: pasar 
de un terreno pelado a una parcela que cuenta con una cobertura vegetal de valor, incrementa significativamente el precio de la finca. En la comarca de Guanacastillo, en la zona Norte, una manzana de tierra pelada de parcelas de reforma agraria escrituradas se vende a $\mathrm{C} \$ 6,000$ (córdobas de finales de 1997). Un campesino socio de LAV que cuenta con una manzana de tierra arborizada en excelente estado afirma que no la vendería por menos de $\mathrm{C} \$ 15,000$. Con la arborización, el valor de la tierra casi se ha triplicado. Y curiosamente, en vez de depreciarse, los árboles son un tipo de capital que sigue creciendo e incrementando su valor.

- La economía se vuelve menos riesgosa: los parceleros han diversificado su producción y ya no dependen únicamente de los granos básicos o del trabajo even- tual como jornaleros. En 1995 los parceleros que ingresaron al programa difícilmente manejaban más de 3 ó 4 diferentes rubros en sus tierras. De una muestra de 74 socios, estos parceleros manejaban en 1996 un promedio de 7 rubros, y en 1997 el promedio era cercano a los 9 rubros.

- La familia logra cubrir sus necesidades básicas y genera un pequeño excedente: el parcelero "palmado" o descapitalizado difícilmente cubre todos los gastos familiares con los ingresos provenientes de la tierra. Para cubrir su déficit tiene que buscar necesariamente algún ingreso extra, más allá de la finca. En cambio, el parcelero que ha consolidado su finca obtiene de ella suficientes ingresos para vivir e incluso saca un pequeño excedente para realizar nuevas inversiones. (gráfico 4).

Gráfico 4

COMPARACIÓN DE UN PARCELERO "PALMADO" Y Y UNO CAPITALIZADO (GASTOS FAMILIARES VS. INGRESO AGROPECUARIO)

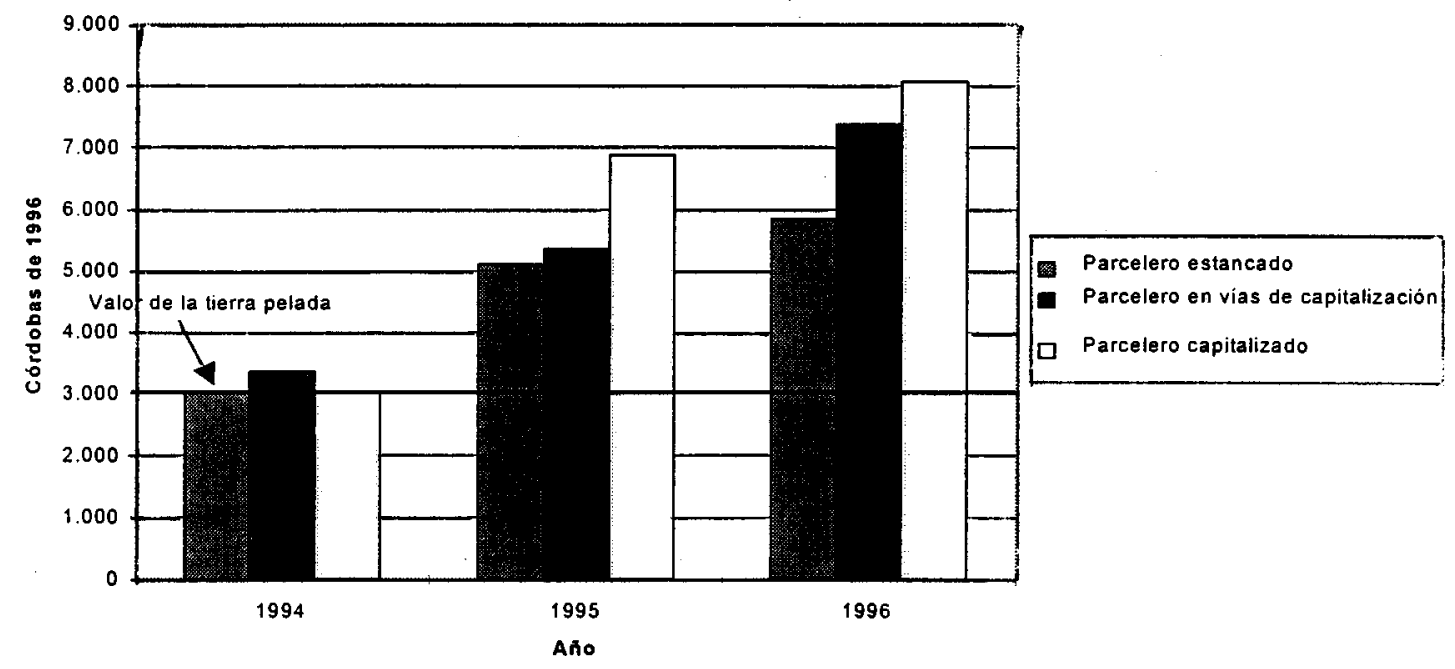


- Se intensifica la producción: Hay más trabajo invertido en la parcela. La familia, ya no necesita tanto vender su fuerza de trabajo; al contrario, comienza a generar empleo contratando algunos mozos durante momentos picos del trabajo. Se reduce el área ociosa de la parcela o las áreas que se alquilan a algún vecino porque no hay capacidad de trabajarlas. Se introducen algunas tecnologías que valorizan mejor el trabajo de la familia y elevan la productividad, como el arado y cultivado con implementos de tracción animal.

\section{Tapando "fugas"}

El crédito es sin duda un apoyo importante para iniciar los procesos de capitalización y estabilización económica de los campesinos. Sin embargo, en ciertas ocasiones no se ve ninguna inversión palpable después del préstamo, más bien pareciera que la plata se la llevó el viento. En la comarca de Guanacastillo (norte de Masaya), un productor recibió C\$3,000 córdobas en crédito, de los cuales ocupó C\$ 900 para pagar antiguas deudas que tenía con algunos familiares y vecinos, y gastó otros C\$1,500 para atender el complicado embarazo y parto que tuvo una de sus hijas. Al final, sólo le quedaron C\$ 600 para invertir en cultivos anuales (maíz), quedándose sin realizar ninguna inversión permanente. El modelo de acumulación de riquezas no funcionó como se esperaba.

Para entender por qué el crédito a veces no es suficiente para levantar al campesino, en LAV se ha desarrollado la idea del "balde roto" (Faurby, 1997). Se compara la economía familiar con un balde que para capitalizarse se tiene que llenar de agua. El crédito es una manguera que inyecta agua desde fuera para subir el nivel del balde, pero el agua muchas veces no se retiene porque el balde está roto, tiene hoyos en su fondo por donde se "fugan" los recursos. Estas fugas tienen que ver con la falta de condiciones básicas para el funcionamiento productivo (falta de un cerco que evite pérdidas por la invasión de animales), el mal manejo de los recursos que ya se tienen (mala aplicación de insecticidas por falta de conocimientos), o el despilfarro incontrolado (utilización de las ganancias para beber guaro, etc.). A veces encontramos también lazos culturales que frenan las dinámicas de acumulación, como la costumbre de realizar grandes gastos durante la muerte de un familiar y sus posteriores conmemoraciones (a los 9 días, 6 meses, aniversarios, etc.). Por muy pobre que sea, la familia se siente en la necesidad de ofrecer comida a todo el vecindario durante estas ceremonias.

Para contribuir a "tapar las fugas" y que el crédito sirva verdaderamente para llenar el balde poco a poco, LAV ha desarrollado un sistema de asesoría que funciona a través de técnicos del programa y promotores de las mismas comunidades. La metodología de trabajo combina la visita y estudio de las fincas de campesinos más avanzados donde se evalúa tanto la integralidad de la producción como aspectos particularmente interesantes de cada caso (el cultivo de un rubro particular como el café o la piña, por ejemplo), 
con capacitaciones más dirigidas en temas claves del programa como la legalización de las propiedades y la producción forestal.

\section{Manejo del subsidio mirando hacia la rentabilidad}

Dar crédito a los sectores frágiles del campesinado implica obviamente un nivel de riesgo significativo, que a la larga se traduce en algún nivel de pérdida que la institución financiera tiene que subsidiar. En el caso de LAV, se estima que entre un $15 \%$ a $20 \%$ de la cartera crediticia tiene pocas posibilidades de recuperación. Este alto porcentaje de cobro dudoso es una pesada carga que se tiene que asumir financieramente como pérdida.

Sin embargo, la esencia de LAV no es el subsidio, sino la búsqueda de la rentabilidad. Los beneficios del crédito se recuperarán de diferentes maneras. Una parte la recuperará la propia entidad financiera, a través del reembolso de los créditos e intereses de los campesinos que desarrollen su capacidad de pago. Otra parte no la recuperará LAV, sino otros actores de la sociedad cuando los habitantes de las ciudades gocen los muebles hechos de la madera que hoy cultivan estos campesinos, o el Estado que recaudará los impuestos sobre el aprovechamiento forestal.

Estando conscientes de que una operación de esta naturaleza conlleva un cierto nivel de subsidio, lo importante no es tanto el subsidio en sí, sino los mecanismos que se crean para que se use eficientemente. Nitlapán optó por crear una entidad especializada que atiende a los parceleros de reforma agraria bajo un sistema de crédito semi-dirigido y asesoría paralela. Para un banco especializado en el negocio financiero quizá no le convenga crear un mecanismo similar, sino establecer programas que contemplen alguna forma de subsidio con nombre y apellido. Lo importante es no ver en la pobreza un motivo de exclusión sino el potencial económico que tiene latente.

\section{Notas}

1. Fanega de café en uva se convierte aproximadamente en 1 quintal de grano seco.

2. Este programa es un complemento del programa de crédito no convencional que Nitlapán creó para atender a sectores más consolidados del campesinado.

\section{Bibliografía}

- Barahona Najlis, Túpac (1997). Las motivaciones y formas en que arborizan los campesinos pobres de Masaya. Managua, Nitlapán. Documento de trabajo.

- D'Exelle, Ben (1997). La arborización en Nicaragua: las tendencias y la racionalidad de los productores de la zona rural de Masaya en cuanto a la arborización. Monografia.

- Faurby, Ove (1997). Estrategias de desarrollo: el reto de llenar un balde roto. Managua, Documento de trabajo.

- Maldidier, C. y Marchetti, P. (1997). El campesino-finquero y el potencial económico del campesinado nicaragüense. Managua, Nitlapán-UCA y USOS/UFSIA. 
- Marín, Mariell José (1998). Evaluación de la capitalización de parcelas de Reforma Agraria en la planicie de Masaya, bajo el sistema de crédito LAV. Managua, Monografía de Licenciatura en Administración de Empresas, UCA. Informe preliminar.

- Nitlapán-UCA (1996). Memoria del seminario "El Crédito y la Reforestación", Managua.

- Nitlapán-UCA (1997). Oportunidades y "fugas" para la capitalización de los parceleros de reforma agraria. Managua, Documento de trabajo.

- Ocdé, Henry (1997). "Ramas de jocote" (Evaluación del Programa Los Arboles Valen, 1995-1997). 